\title{
A Theoretical Model For Accounting For Cost Variance In The Residential Home Building Industry
}

Mark D. Law, Bloomsburg University, USA

\begin{abstract}
The purpose of this study was to propose a theoretical model for home building contractors. The theoretical framework proposed was formulated from a systems approach focusing on the principles of general systems theory and applying the theory of single-loop learning to the task of a real-time cost variance calculation. In creating the model, the researcher first looked at the concept of general systems theory, applying the system concept using a systems approach. This approach has led to the development of the theoretical model for the home building industry. In the center of the model is the cost variance system interacting with the individual subsystems; estimating, accounting, standards, and technology. This model outlines the importance of four separate subsystems and their interrelationships in the calculation of cost variance. The model in this study has led to several important implications and recommendations for the home building industry
\end{abstract}

Keywords: Cost Variance; Home Construction; Home Building

\section{INTRODUCTION}

ith increasing demands from customers for quality, progressively more complex building forms, and growing competition in a global marketplace, the challenge to deliver profitable projects for home building contractors becomes increasing difficult. In the construction industry, a project is a job or venture undertaken. The project entails the flow of information from the client's input through to the output in the form of the physical structure. The progression of the loop is repeated until the structure is completed. As such, the construction project is seen as a unique and complete job involving many interrelated tasks (Al-Jibouri \& Mawdesley, 2002).

The task is complicated even further when factoring in timelines and budgets. In the immediate future, without efficient use of methods which include information technology to control costs, the ability to be competitive in the construction arena will be significantly altered ("Partnership for", 2001). Currently, there is an abundance of hardware and software on the market to support the small to medium size construction firms. The process of linking the estimating system to the job cost system has become obtainable and affordable. Such information systems allow for not only high performance but also low cost. Construction firms can cost effectively use information technology to monitor and improve the job cost and estimating functions (Rammes \& Noel, 2001; Jackson, 2001). However, it appears that many firms are not taking advantage of the technology in managing a complex building process ("Partnership for", 2001). In an increasing competitive environment, construction firms must have a better understanding of information technology in relation to the management of projects to facilitate operations in a complex environment ("Partnership for", 2001). Some of the top reasons for construction contractor failures are poor estimating, job costing, cash flow, and accounting systems, all revolving around information technology (Davidson \& Maguire, 2003).

In summary, the construction industry is predicated on the flow of information, and that information is the vehicle that drives the business. There are many information flows in a construction project which makes it difficult 
to manage; however, the management of this information is vital for a successful project (Mead, 2001). One of the most important flows of information revolves around the cost variance calculation which is determined by subtracting the actual costs from the estimated (budgeted) costs. Calculating cost variance is the foundation for controlling costs on a project. Cost variance can make the difference between success and failure on a job in a highly competitive market (Christofferson, 2000). Subsequently, information is only valuable if it is accurate, relevant, and delivered to the appropriate people in a timely manner. Information technology can help manage the flow of information to increase the accuracy and efficiency of the business operations and ultimately the business process ("Partnership for", 2001).

\section{FRAMEWORK}

The theoretical framework proposed (Figure 1) was formulated from a systems approach focusing on the principles of general systems theory and applying the theory of single-loop learning to the task of a real-time cost variance calculation. In creating the model, the researcher first looked at the concept of general systems theory introduced by Ludwig Von Bertalanffy in 1937 in his lectures and discussions within the classroom and subsequently, after the Second World War, formally in writings and publications. General systems theory is based on the principle of wholeness of the entire system and the many variables that interact within that system. It is concerned with the interaction and interrelationship of those variables producing more when they are working in concert than when they are working in seclusion (Von Bertalanffy, 1975). Von Bertalanffy (1952) in his classic work Problems of Life, explains:

The properties and modes of action of higher levels are not explicable by the summation of the properties and modes of action of their components taken in isolation. If, however, we know the ensemble of components and the relations existing between them, then the higher levels are derivable from the components. (p. 148)

The concept of general systems theory was not unique to Von Bertalanffy. The systems ideal has been dated as far back to Aristotle's statement "the whole is more than the sum of the parts" (Von Bertalanffy, 1975). However, Von Bertalanffy brought the systems theory to the forefront. With this in mind, Von Bertalanffy envisioned an interdisciplinary general systems theory that could be transferred to different departments of science and other fields since the general systems theory is pertinent and relevant to phenomena in various fields (Von Bertalanffy, 1968).

The concepts and ideals of holistic thinking are important in the systems approach and involve the notion that the whole is not the same as, and is actually greater than, the sum of the individual parts. Patton (2002) explains "a system cannot validly be divided into independent parts as discrete entities of inquiry because the effects of the behavior of the parts on the whole depend on what is happening to the other parts" (p. 120). Holistic thinking is fundamental and essential to the systems-approach perspective. A system cannot be understood by separating the parts for individual analysis in isolation because the role and significance of the parts within the system is lost (Patton, 2002). According to Kast and Rosenzweig (1985), a "systems approach provides the basis for integration by giving us a way to view the total organization in interaction with its environment and for the conceptualization of relationships among internal components or subsystems" (p. 102).

Applying the system concept using a systems approach has led to the development of the theoretical framework for the home building industry. At the core of the model are the four subsystems involved in the study, illustrated in the form of a Venn diagram (Figure 2). The center of the model represents the variation and interaction of four variables. The Venn diagram in the center of the model shows a cost variance system and the individual subsystems; estimating, accounting, standards, and technology and their influence of the suprasystem, cost variance. These four subsystems were selected out of importance and in order to concentrate the research effort. This model outlines the importance of four separate subsystems and their interrelationships in the calculation of cost variance. The four ovals representing standards, accounting, estimating, and technology are shown because each represents a system in their own right defined by distinct boundaries while at the same time shows their dependency and role in the larger cost variance system. In looking at the larger cost variance circle, the unoccupied space after the four subsystems in the circle corresponds to the holistic concept which exemplifies the principle that the cost variance system is greater than the aggregate of its subsystems. 
Figure 1 shows the variables which are subsystems in the cost variance system, when working in tandem instead of isolation, can increase the effectiveness of the entire system. This relationship is represented by the two circles. The inner circle represents the cost variance calculation and the factors that go into the calculation. The outer circle symbolizes the greater efficiency of the cost variance calculation when those factors interact and interrelate, mutually and collectively, as expressed in a holistic approach. No longer can cost variance factors be looked at in separation but rather as a system of interrelated and interacting components.

Now that the system and components have been defined, it is important to look at the outer portion of the theoretical framework guiding this study (Figure 1). The concept of single-loop learning was incorporated into the input, process, output function of the cost variance calculation. In the cost variance calculation, the estimated costs and actual costs are entered into the system as inputs. These items are subsequently processed and result in the cost variance as an output. The researcher of the study sought to find if the cost variance is calculated efficiently and timely, and whether the cost variance is processed back into the system as an input to monitor the project and to keep the project on time and budget. As the model flows, cost variance is calculated as an output, the cost variance information obtained should be monitored and compared to the goals. If the goals are not on target, steps needed for corrective action should be sent back into the system as input.

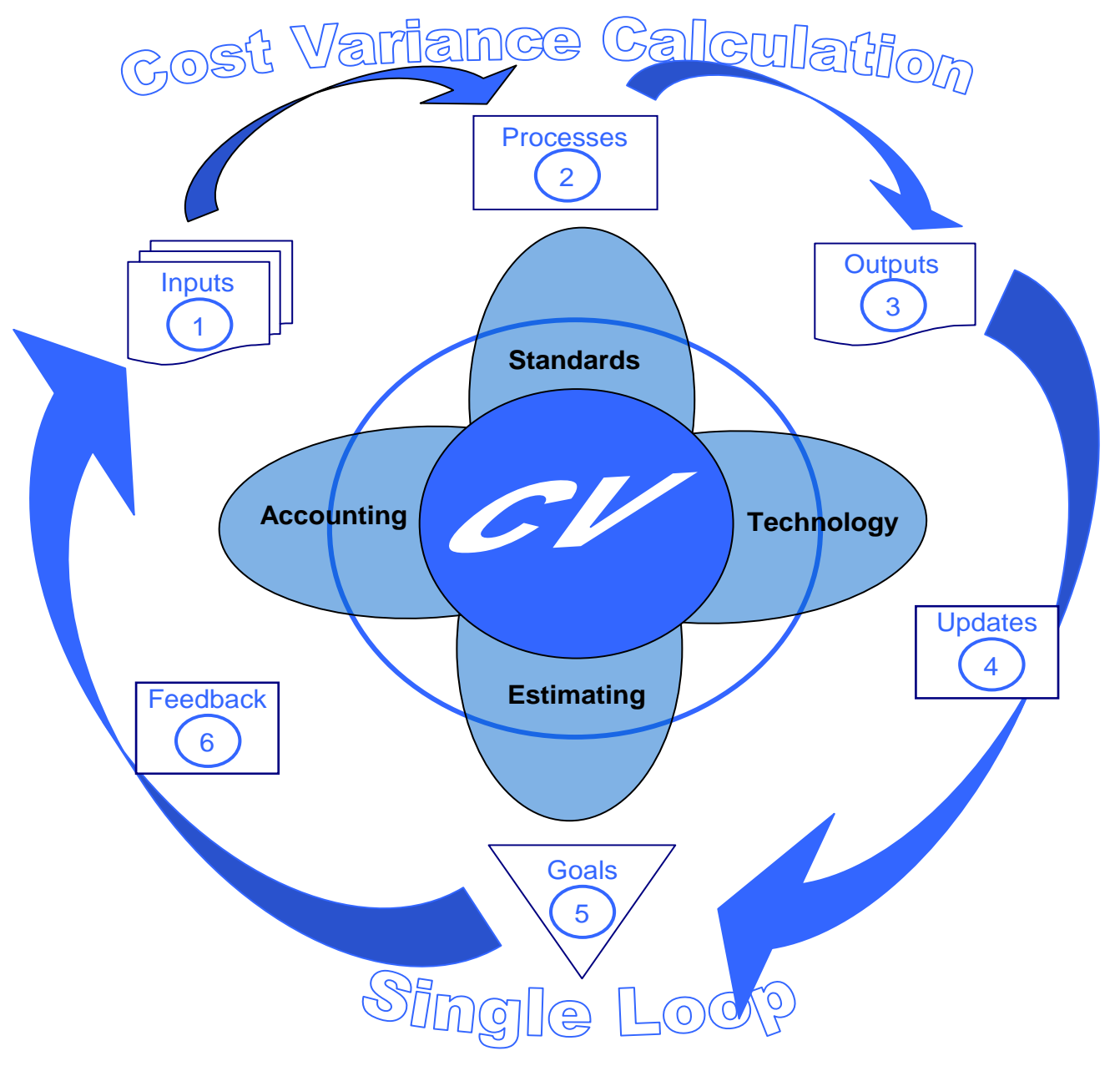

Figure 1. Cost variance calculation applying single-loop learning centered on a holistic approach 
Specifically, the study integrated the concept of single-loop learning system into the framework as a feedback mechanism applied in regard to the utilization of a real-time cost variance by Pennsylvania home building contractors. Argyris and Schon developed the term single-loop learning from their research work on organizational learning. Argyris and Schon (1978) define single-loop learning in the realm of error detection and correction in organizational learning as "when the error detected and corrected permits the organization to carry on its present policies or achieve its present objectives, then that error-detection-and-correction process is single-loop learning" (p. 2). Single-loop learning involves obtaining continuous information, making revisions and adaptations to internal and external conditions, and undertaking appropriate corrective action when necessary in order to stay on course of the stated outcomes or goals.

In summary, Figure 1 displays the model titled "cost variance calculation applying single-loop learning centered on a holistic approach" designed for the study. The model, built from existing theories of general systems, systems approach, and single-loop learning, shows the cost variance system incorporated into and centered on the suprasystem cost variance. The model illustrates the interaction of the subsystems throughout the inputs, processes, and outputs stages of the cost variance calculation while incorporating a feedback loop within the suprasystem. The model is designed to specifically address the efficiency of the total cost variance system by the utilization of a feedback mechanism (single-loop) for updating information. The cost variance management system provided a dynamic system environment and served as the model to that was used to test for cost variance implementation by Pennsylvania home building contractors.

\section{CONCLUSIONS}

Home building contractors could benefit from using information technology more efficiently in order to manage construction projects to stay on time and budget and increase profitability ("Partnership for", 2001). In order to keep the project on time and budget, financial information in the form of reports are vital and must be prepared on time and be reliable. Timely information, with the necessary detail, is critical in order to make the correct business decisions and anticipate any problems to keep the project on schedule and profit in line (Davidson \& Maguire, 2003).

Due to the lack of attention, investment, and innovation of information technology in the construction industry, many firms still operate on the preverbal "islands of automation" in which hardware, software, and processes are often incongruent and incompatible (Alshawi \& Faraj, 2002). This is a particular concern for the construction industry because the majority of work involves projects that are broken down into isolated stages. A holistic approach using information technology while incorporating both the estimating and accounting functions into a system can lead to greater synergy in the cost control practices. According to Harrington (1991), "synergy is achieved through the interaction of a system's subsystems which allows it a greater performance than the total of the subsystems as individuals" (p.87).Looking forward, the future of the construction industry involves integrating various functions involved in the building and management of a project. The principle functions of estimating and accounting conducted through the use of information technology and standards, can work more efficiently, holistically, in one system instead of in isolation fragmented in separate systems. The research advances the theory that the home building industry as a whole lacks an integration of information technology and proposes a model to facilitate integration of various aspects of the home building industry.

\section{AUTHOR INFORMATION}

Mark D. Law, Bloomsburg University, E-mail: mlaw@bloomu.edu.

\section{REFERENCES}

1. Al-Jibouri, S. H. \& Mawdesley, M. J. (2002). A knowledge based system for linking information to support decision making in construction. Electronic Journal of Information Technology in Construction. 7, 83-100. Retrieved June 14, 2003, from http://www.itcon.org/2002/6

2. Alshawi, M. \& Faraj, I. (2002). Integrated construction environments: technology and implementation. Construction Innovation, 2(1), 33-51. 
3. Argyris, C. \& Schon, D. A. (1978). Organizational learning: A theory of action perspective. AddisonWesley: Reading, MA.

4. Christofferson, J. P. (2000). Unlocking the power for home builders: Estimating with Microsoft excel. Washington DC: Home Builder Press.

5. Davidson, R. A. \& Maguire, M. G. (2003). Ten most common causes of construction contractor failures. Journal of Construction Accounting \& Taxation, 13(1), 35-37.

6. Harrington, J. (1991). Organizational Structure and Information Technology., New York: Prentice-Hall.

7. Kast, F. E. \& Rosenzweig, J. E. (1985). Organization and Management., New York: McGraw-Hill.

8. Mead, S. P. (2001). Developing benchmarks for construction information flows. Journal of Construction Education, 6(3), 155-166.

9. Patton, M. Q. (2002). Qualitative Research \& Evaluation Methods $3^{\text {rd }}$ ed. Thousand Oaks, CA: Sage Publications, Inc.

10. Partnership for Advancing Technology in Housing. (2001). Information technology to accelerate and streamline home building. (NAHB Research Center). Upper Marlboro, MD.

11. Rammes, J. \& Noel, P. (2001). Technology in construction. Journal of Construction Accounting \& Taxation, 11(5), 13.

12. Von Bertalanffy, L. (1975). Perspectives on General System Theory-Scientific-Philosophical Studies., New York: George Braziller, Inc.

13. Von Bertalanffy, L. (1968). General System Theory-Foundations, Development, Applications., New York: George Braziller, Inc. 
NOTES 